DOI:10.33099/2311-7249/2021-40-1-175-180

УДК: 351.813 .12

Олена Вікторівна Дергильова (кандидат технічних наук, с.н.с.)

Національний університет оборони Украӥни імені Івана Черняховського, Київ, Украӥна

\title{
МОДЕЛЬ НАУКОВО-ТЕХНІЧНОЇ СФЕРИ СИСТЕМИ ЗАБЕЗПЕЧЕННЯ ВОЄННОЇ БЕЗПЕКИ ДЕРЖАВИ
}

\begin{abstract}
В умовах відсутності в обраній предметній області закінченої теорії незамінним інструментом дослідника залишається модель об'єкта чи явища, щฺо підлягає дослідженню. Не зважаючи на конкретні особливості моделі, слід зазначити, щзо прочес отримання необхідної моделі завжди базується на ретельному вивченні об'єкта-оригінала. Якщо механізм функиіонування об'єкта-оригінала доступний для розкриття та розуміння, а його окремі складові піддаються повному (в межах дослідження) вивченню, то в такому випадку природною є побудова та подальше застосування імітаційної моделі.

Але теорія воєнної безпеки держави має справу з об’єктами та явищами, властивості яких в різній мірі, але завжди знаходяться в залежності від “людського фактору”, отже важко піддаються формалізації. Цей факт означає, щчо, як правило, “істинний” механізм функиіонування об'єкту дослідження залишається для дослідника скритим, а вивчення властивостей окремих складових об 'єкта дослідження в потрібній мірі неможливе. Проте $i$ в таких випадках є потреба застосування в дослідженні відповідних моделей, причому сам об'єкт дослідження уявляється як деякий “чорний ящчик”.

Одним із різновидів видів моделювання, який враховує і притаманні певному суб' єкту особливості сприйняття ситуації, і нечіткість опису ситуаџії та об'єкту моделювання, та базується на застосуванні формальних методів, є когнітивне моделювання.

В статті розглядається когнітивна модель науково-технічної сфери як складової забезпечення воєнної безпеки держави. На основі відомої моделі розглянуто способи визначення структури та параметрів моделі, ї̈ застосування для визначення найбільш впливових факторів на цілі функціонування системи, а також способи модифікаиії моделі для урахування поточних реалій.
\end{abstract}

Ключові слова: воєнна безпека держави, когнітивна модель, лінгвістичні змінні, вектор иілей, вектор управління.

\section{Вступ}

Постановка проблеми. В умовах відсутності в обраній предметній області закінченої теорії незамінним інструментом дослідника залишається модель об'єкта чи явища, що підлягає дослідженню. Не зважаючи на конкретні особливості моделі, слід зазначити, що процес отримання необхідної моделі завжди базується на ретельному вивченні об'єкта-оригінала. Якщо механізм функціонування об'єкта-оригінала доступний для розкриття та розуміння, а його окремі складові піддаються повному (в межах дослідження) вивченню, то в такому випадку природною є побудова та подальше застосування імітаційної моделі.

Але теорія воєнної безпеки держави має справу 3 об'єктами та явищами, властивості яких в різній мірі, але завжди знаходяться в залежності від “людського фактору”, отже важко піддаються формалізації. Цей факт означає, що, як правило, “істинний” механізм функціонування об'єкту дослідження залишається для дослідника скритим, а вивчення властивостей окремих складових об'єкта дослідження в потрібній мірі неможливе. Проте і в таких випадках є потреба застосування в дослідженні відповідних моделей, причому сам об’єкт дослідження уявляється як деякий “чорний ящик”.

Одним із різновидів видів моделювання, який враховує i притаманні певному суб'єкту особливості сприйняття ситуації, і нечіткість опису ситуації та об'єкту моделювання, та базується на застосуванні формальних методів, $є$ когнітивне моделювання.

Аналіз останніх досліджень і публікацій. За останні двадцять років широкої відомості набула відносно невелика кількість формальних методів оцінки стану воєнної безпеки держави та розрахунків заходів щодо іiі забезпечення. Так, широковідомими $\epsilon$ практично єдиний метод прогнозування динаміки воєнно-політичної обстановки на основі методології сценарного аналізу соціально-економічних систем [1] та методика аналізу та оцінки рівня національної безпеки та іiі 
складових на основі порівняльного аналізу на основі методів таксономії 3 елементами факторного аналізу [2]. Наряду з зазначеними вітчизняними розробками на увагу заслуговує робота російських колег, присвячена питанням когнітивного моделювання воєнної безпеки держави [3]. Далі буде розглянута одна із складових цього комплексу моделей - модель науково-технічної сфери.

Метою статті є розкриття методів визначення структури та параметрів моделі науково-технічної сфери забезпечення воєнної безпеки на основі вже відомої моделі, порядку застосування моделі для визначення найбільш впливових факторів на цілі функціонування останньої, а також способів модифікації моделі для урахування поточних реалій.

\section{Виклад основного матеріалу дослідження}

У [3] наведено комплекс когнітивних моделей оборонно-промислового комплексу Росії. Однією $з$ складових цього комплексу $\epsilon$ модель науковотехнічної сфери. Слід зазначити, що когнітивна модель $\epsilon$ відображенням сприйняття деяким суб'єктом певної ситуації. В основі когнітивної моделі лежить когнітивна карта, для математичної формалізації якої застосовується нечітка логіка, теорія графів та теорія матриць.

Взагалі, процедура когнітивного моделювання в [3] представлена як циклічний процес, що містить п'ять взаємопов'язаних етапів: когнітивна структуризація, структурний аналіз когнітивної моделі, сценарне моделювання розвитку ситуації, оцінювання та інтерпретація результатів моделювання, когнітивний моніторинг ситуації.

Формалізована когнітивна карта є результатом когнітивної структуризації, метою якої $\epsilon$ : формування множини базисних факторів, визначення початкових параметрів базисних факторів, визначення причинно-наслідкових відношень між базисними факторами та визначення параметрів таких відношень. Також на множині базисних факторів задаються підмножини цільових факторів (що найбільше характеризують стан об'єкту управління) та факторів управління (пов'язані 3 об'єктом управління чи зовнішнім середовищем). При цьому параметри базисних факторів та причиннонаслідкових зв'язків між ними є лінгвістичними змінними, можливі значення яких наведені в табл. 1.

Таблиця 1

Значення лінгвістичних змінних

\begin{tabular}{|l|l|c|}
\hline \multicolumn{1}{|c|}{$\begin{array}{c}\text { Лінгвістичне значення змінної } \\
\text { (фактору) }\end{array}$} & \multicolumn{1}{|c|}{ Лінгвістичне значення зв'язку } & Числове значення \\
\hline Не змінюється & Не впливає & 0 \\
\hline Дуже слабко зростає (спадає) & Дуже слабко підсилює (послаблює) & $0,2(-0,2)$ \\
\hline Слабко зростає (спадає) & Слабко підсилює (послаблює) & $0,4(-0,4)$ \\
\hline Помірно зростає (спадає) & Помірно підсилює (послаблює) & $0,6(-0,6)$ \\
\hline Сильно зростає (спадає) & Сильно підсилює (послаблює) & $0,8(-0,8)$ \\
\hline Дуже сильно зростає (спадає) & Дуже сильно підсилює (послаблює) & $1,0(-1,0)$ \\
\hline
\end{tabular}

Базисні фактори когнітивної моделі науковотехнічної сфери, їх початкові значення (визначені в [3] методом кодування та аналізу текстів) та оцінка динаміки факторів (ОДФ) наведені в табл. 2. ОДФ є одним із результатів структурного аналізу когнітивної карти. Для його проведення висувається гіпотеза цілепокладання, згідно з якою особа, що приймає рішення (ОПР), може вказати бажаний напрямок зміни базисних факторів (бажане приймає значеня "+1", небажане - "-1", "0" - оцінка ускладнена). Іншими цілями структурного аналізу є перевірка вектора цілей на непротирічність, перевірка узгодженості факторів управління 3 вектором цілей та оцінка ефективності інтегрального впливу факторів управління на цільові.

У таблиці використовуються загальноприйняті скорочення (ОПК - оборонно-промисловий комплекс, НДР - науково-дослідна робота, ДКР дослідно-конструкторська робота).

Когнітивна модель у вигляді зваженого орієнтованого графа, на якому вказана вага зв’язків, наведена на рис.1. Номер вершини графа є номером фактора в табл. 2.

Таблиця 2

Базисні фактори, їх початкові значення ОДФ

\begin{tabular}{|c|l|c|c|}
\hline № 3/п & \multicolumn{1}{|c|}{ Назва фактору } & Значення & ОДФ \\
\hline 1 & Науково-технічний потенціал ОПК & 0 & 1 \\
\hline 2 & Кількість кваліфікованих наукових робітників на підприємствах ОПК & $-0,2$ & 1 \\
\hline 3 & Науково-технологічний заділ підприємств ОПК & $-0,4$ & 1 \\
\hline 4 & Матеріально-технічна база наукових досліджень & $-0,6$ & 1 \\
\hline 5 & Привабливість наукової роботи на підприємствах ОПК & $-0,4$ & 1 \\
\hline
\end{tabular}


Strategic communications and special purpose cognitive systems

\begin{tabular}{|c|l|c|c|}
\hline № з/п & \multicolumn{1}{|c|}{ Назва фактору } & Значення & ОДФ \\
\hline 6 & Кваліфікація наукових робітників підприємств ОПК & $-0,4$ & 1 \\
\hline 7 & Об’єм та інтенсивність НДР та ДКР & 0,4 & 1 \\
\hline 8 & Об’єм зовнішніх інвестицій & 0,2 & 1 \\
\hline 9 & Рівень заробітної плати наукових працівників підприємств ОПК & $-0,6$ & 1 \\
\hline 10 & Державне фінансування НДР та ДКР & 0 & 1 \\
\hline 11 & Власні кошти підприємств ОПК & 0 & 1 \\
\hline 12 & Витрати підприємств ОПК на проведення НДР та ДКР & 0 & -1 \\
\hline 13 & Прибуток підприємств ОПК & 0 & 1 \\
\hline 14 & Інтенсивність передачі технологій подвійного призначення & 0 & 1 \\
\hline
\end{tabular}

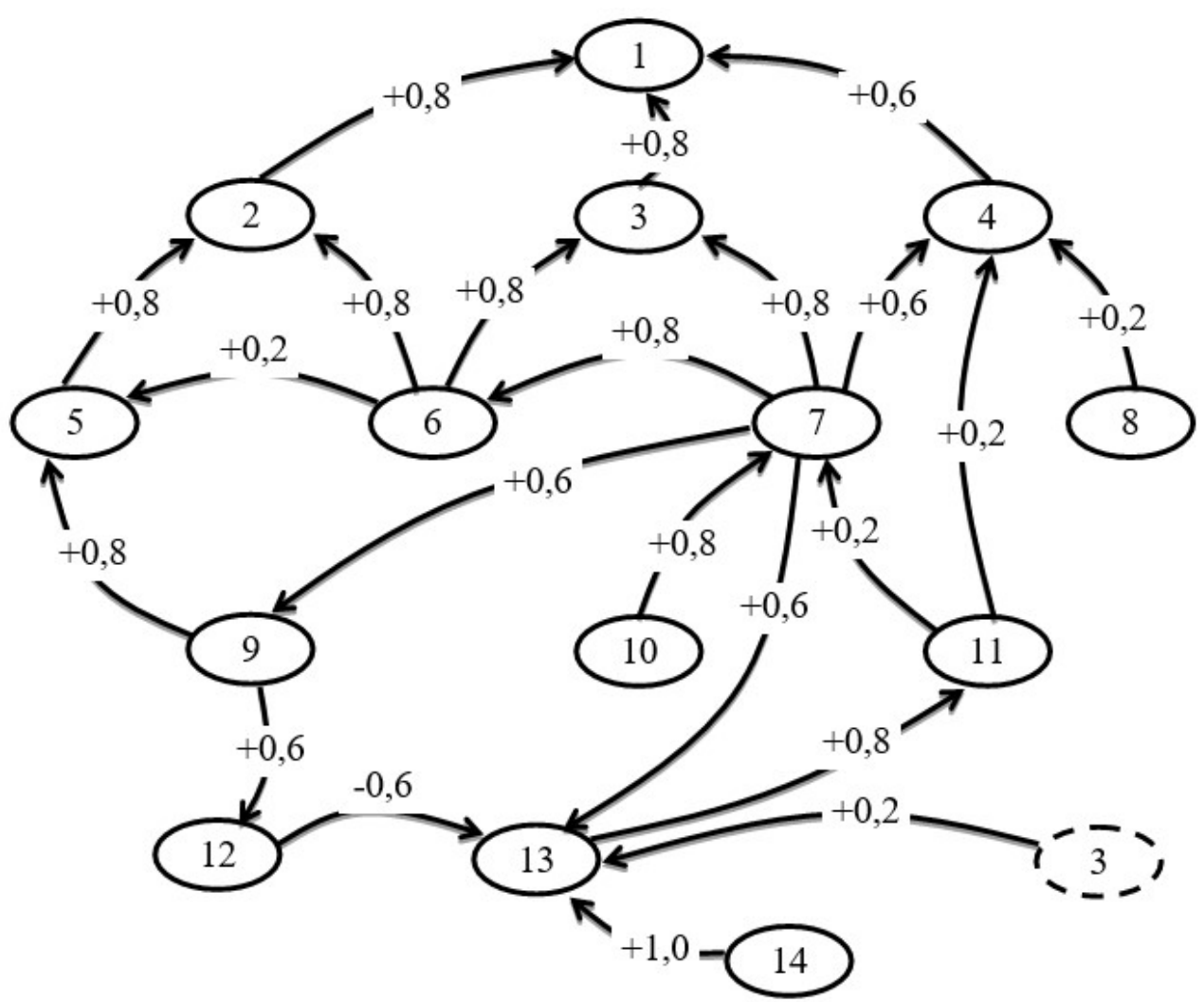

Рис.1. Когнітивна модель науково-технічної сфери

Математика когнітивної моделі зводиться до того, що всі взаємодії факторів визначаються тільки матрицею суміжності вершин орієнтованого графа. У даному випадку матриця суміжності має вигляд

$W=\left(\begin{array}{cccccccccccccc}0 & 0 & 0 & 0 & 0 & 0 & 0 & 0 & 0 & 0 & 0 & 0 & 0 & 0 \\ +0,8 & 0 & 0 & 0 & 0 & 0 & 0 & 0 & 0 & 0 & 0 & 0 & 0 & 0 \\ +0,8 & 0 & 0 & 0 & 0 & 0 & 0 & 0 & 0 & 0 & 0 & 0 & +0,20 \\ +0,6 & 0 & 0 & 0 & 0 & 0 & 0 & 0 & 0 & 0 & 0 & 0 & 0 & 0 \\ 0 & +0,8 & 0 & 0 & 0 & 0 & 0 & 0 & 0 & 0 & 0 & 0 & 0 & 0 \\ 0 & +0,8+0,8 & 0 & +0,2 & 0 & 0 & 0 & 0 & 0 & 0 & 0 & 0 & 0 \\ 0 & 0 & +0,8+0,6 & 0 & +0,8 & 0 & 0+0,60 & 0 & 0 & +0,60 \\ 0 & 0 & 0 & +0,2 & 0 & 0 & 0 & 0 & 0 & 0 & 0 & 0 & 0 & 0 \\ 0 & 0 & 0 & 0 & +0,8 & 0 & 0 & 0 & 0 & 0 & 0 & +0,6 & 0 & 0 \\ 0 & 0 & 0 & 0 & 0 & 0 & +0,80 & 0 & 0 & 0 & 0 & 0 & 0 \\ 0 & 0 & 0 & +0,2 & 0 & 0 & +0,20 & 0 & 0 & 0 & 0 & 0 & 0 \\ 0 & 0 & 0 & 0 & 0 & 0 & 0 & 0 & 0 & 0 & 0 & 0 & -0,60 \\ 0 & 0 & 0 & 0 & 0 & 0 & 0 & 0 & 0 & 0 & 0,8 & 0 & 0 & 0 \\ 0 & 0 & 0 & 0 & 0 & 0 & 0 & 0 & 0 & 0 & 0 & 0 & +1 & 0\end{array}\right)$.

Визначення змін значень параметрів базисних факторів визначається видом математичної моделі і є суттю сиенарного моделювання. У [3] розглядаються тільки лінійні когнітивні моделі (засновані на лінійній алгебрі), для яких в основу моделі покладена гіпотеза про те, що поточне прирощення кожного фактору є зваженою сумою поточних прирощень факторів, які на цей фактор впливають. Початкові значення факторів (а точніше, в нашому прикладі - значення зміни факторів) на момент часу $t$ задаються вектором

$$
X^{T}(t)=\left(x_{1}(t), x_{2}(t), \ldots, x_{14}(t)\right) .
$$

Для наведеного прикладу

$$
X^{T}(t)=(0 ;-0,2 ;-0,4 ;-0,6 ;-0,4 ;-0,4 ; 0,4 ; 0,2 ;-0,6 ; 0 ; 0 ; 0 ; 0 ; 0)
$$

Тоді значення вектору зміни значень факторів в наступний момент часу в матричній формі задається рівнянням

$$
X^{T}(t+1)=W \cdot X(t)
$$

Слід зазначити, що момент часу $t+1$ жорстко визначається тим часовим інтервалом, на якому здійснена оцінка початкових значень зміни факторів. Наприклад, якщо початкові значення змін факторів оцінювалися за один місяць, то i 
момент часу $t+1$ настане після моменту часу $t$ через один місяць. Також варто звертати увагу ще й на таку особливість наведеної когнітивної моделі, як затухання наслідків разового локального впливу. Це передбачає,що будь-який стан системи (точніше, пї моделі) $є$ стійким. Достатньою умовою затухання наслідків одиничного впливу є те, що відображення вектора $X(t)$ у вектор $X(t+1)$ повинно бути стискаючим. Ця умова забезпечується, якщо значення матриці $W$ заключні в інтервалі від -1 до +1 (що має місце у даному випадку).

Легко побачити шляхом багатокрокового застосування (1), що запропонована модель 3 наведеними початковими даними та вагами зв'язків досить швидко переходить у сталий стан, тобто коли зміни значень факторів не відбуваються (точніше, зміни стають невідчутно малими та коливаються навколо нуля). В такий стан ми переходимо вже на 10-му кроці застосування моделі.

Якщо відокремити модель науково-технічної сфери із комплексу когнітивних моделей ОПК [3], то вектор цілей складається 3 факторів, наведених в табл. 3 , вектор управління наведено в табл. 4 .

Таблиця 3

Вектор цілей

\begin{tabular}{|c|l|c|c|c|}
\hline № 3/п & \multicolumn{1}{|c|}{ Назва фактору } & Важливість & Категорія & Значення \\
\hline 1 & Науково-технічний потенціал ОПК & 5 & 1 & 0,8 \\
\hline 11 & Власні кошти підприємств ОПК & 4 & 1 & 0,8 \\
\hline
\end{tabular}

Таблиця 4

Вектор управління

\begin{tabular}{|c|l|c|}
\hline № 3/п & \multicolumn{1}{|c|}{ Назва фактору } & Цінність ресурсу \\
\hline 5 & Привабливість наукової роботи на підприємствах ОПК & 0 \\
\hline 8 & Об’єм зовнішніх інвестицій & 2 \\
\hline 12 & Витрати підприємств ОПК на проведення НДР та ДКР & 0 \\
\hline 14 & Інтенсивність передачі технологій подвійного призначення & 0 \\
\hline
\end{tabular}

Якщо фактор віднести до цільового та позначити його через $y_{i}$, а ОДФ відповідно через $r_{y_{i}}$, то умову непротирічності цілей можна записати як

$$
r_{y_{i}} \times r_{y_{j}}=\operatorname{sign} q_{i j}, \forall y_{i}, y_{j} \in y
$$

де $q_{i j} \quad-$ елемент матриці $Q \cong(E-W)^{-1}$ (результат транзитивного замикання матриці суміжності).

Не важко перевірити, що $q_{1,11}=0$, $q_{11,1}=0,68, \quad$ отже поставлені цілі $\epsilon$ непротирічними i мають односторонній позитивний зв'язок.

Якщо фактор управління позначити $u_{i}$, тоді вектор управління $u$ є узгодженим 3 вектором цілей $y$, якщо для кожної координати $u_{i}$ вектора $u$ можна вказати такий знак, що для результуючого знакового вектора sign $u$.

$$
r_{y_{i}}=\operatorname{sign} q_{i j} \times \operatorname{sign} u_{i}, \forall y_{i} \in Y, \forall u_{i} \in U
$$

Також не важко перевірити, що остання умова теж виконується.

Для формальної оцінки показника ефективності фактора управління $E\left(u_{i}\right)$ розраховується абсолютне значення суми коефіцієнтів інтегрального впливу даного фактора, помножені на ОДФ цільових факторів.

$$
E\left(u_{i}\right)=\left|\sum_{j=1}^{m} q_{i j} r_{y_{i}}\right|
$$

Тут індекс $i$ відноситься до управлінь, а індекс $j$ - до цілей.

Оскільки ОДФ цілей у даному прикладі $\epsilon$ додатними, їх можна опустити, тоді в результаті маємо

$$
\begin{gathered}
E\left(u_{5}\right)=\left|q_{5,1}+q_{5,11}\right|=0,64, \\
E\left(u_{8}\right)=\left|q_{8,1}+q_{8,11}\right|=0,12, \\
E\left(u_{12}\right)=\left|q_{12,1}+q_{12,11}\right|=0,8, \\
E\left(u_{14}\right)=\left|q_{14,1}+q_{14,11}\right|=1,44 .
\end{gathered}
$$

Таким чином, аналіз показує, що найбільш сильним впливом на цілі функціонування науковотехнічної сфери забезпечення воєнної безпеки держави є фактор інтенсивності передачі технологій подвійного призначення, другим за ним $є$ фактор витрат на проведення НДР та ДКР.

\section{Висновки і перспективи подальших досліджень}

Отже, наразі розглянуто структуру та параметри когнітивної моделі науково-технічної сфери, а також порядок застосування цієї моделі для визначення найбільш впливових факторів на цілі функціонування науково-технічної сфери.

Розглянута модель була розроблена для комплексу когнітивних моделей ОПК Росії, проте, 
враховуючи до недавнього часу наявність дуже сильного зв'язку між ОПК Росії та України, можна вважати дану модель корисною i для вітчизняних фахівців, які займаються питаннями воєнної безпеки держави. Безперечно, що для такого використання модель потребує деяких уточнень. Скоріше за все, перелік базових факторів та зв'язки між ними для реалій українського ОПК залишаться ті ж самі, або зазнають досить незначних змін. А от ваги зв'язків та початкові стани факторів можуть суттєво відрізнятися. Для оцінки їх числових значень можна також використати методику гіпертекстового моделювання, як і в [3], коли числові оцінки отримуються шляхом кодування тексту та анкетування. Можна використати один з експертних методів оцінки, який буде задовольняти потреби дослідників. Можна також скористатися оптимізаційними методами, якщо відома деяка попередня

\section{Jimepamypa}

1. Богданович В. Ю. Теоретические основы анализа проблем национальной безопасности государства в военной сфере: Монография / Богданович В. Ю. // К. : Основа, 2006. -296 с.

2. Косевцов В. О. Методичний підхід до аналізу й оцінки рівня національної безпеки та ії складових / статистика функціонування науково-технічної сфери. Розглянемо цей підхід трішечки докладніше.

Модель науково-технічної сфери містить багато рівнянь типу

$$
x_{j}=a_{i j} x_{i}
$$

Якщо для змінних $x_{j}$ та $x_{i}$ відомі їх значення в попередні моменти часу, наприклад задані у вигляді векторів $X_{j}^{T}=\left(x_{j}(t-2) ; x_{j}(t-1) ; x_{j}(t)\right) \quad$ та $X_{i}^{T}=\left(x_{i}(t-2) ; x_{i}(t-1) ; x_{i}(t)\right), \quad$ тоді коефіцієнт $a_{i j}$ можна легко визначити за методом найменших квадратів (МНК) $a_{i j}=\left(X_{i}^{T} X_{i}\right)^{-1} X_{i}^{T} X_{i}$.

Якщо уточнення потребуватимуть не тільки параметри моделі, а i iii структура (уточнення наявних зв'язків), тоді можна використати метод структурно-параметричної ідентифікації моделей на основі того ж МНК, наприклад, широко відомий метод групового врахування аргументів.

Косевцов В. О., Бінько І. Ф., Матвієвський О. М. // Наука і оборона. - 1995. - № 1. - С. 74-77.

3. Макаренко Д.И., Хрусталев Е.Ю. Концептуальное моделирование военной безопасности государства / Д.И. Макаренко, Е.Ю. Хрусталев; Центр, экон.-мат. ин-т РАН; Ин-т проблем управления им. В.А. Трапезникова РАН. М.: Наука, 2008. - 303 с.

\title{
МОДЕЛЬ НАУЧНО-ТЕХНИЧЕСКОЙ СФЕРЫ СИСТЕМЫ ОБЕСПЕЧЕНИЯ ВОЕННОЙ БЕЗОПАСНОСТИ ГОСУДАРСТВА
}

\author{
Олена Вікторівна Дергилева (кандидат технических наук, с.н.с.)
}

\author{
Национальный университет обороны Украины имени Ивана Черняховского, Киев, Украина
}

В условиях отсутствия в выбранной предметной области законченной теории незаменимым инструментом исследователя остается модель объекта или явления, подлежащего исследованию. Несмотря на конкретные особенности модели, следует отметить, что процесс получения необходимой модели всегда базируется на тщзательном изучении объекта-оригинала. Если механизм функиионирования объекта-оригинала доступен для раскрытия и понимания, а его отдельные составляющие поддаются полному (в рамках исследования) изучению, то в таком случае естественной является построение и дальнейшее применение имитационной модели.

Но теория военной безопасности государства имеет дело с объектами и явлениями, свойства которых в разной степени, но всегда находятся в зависимости от "человеческого фактора", так что трудно поддаются формализации. Этот факт означает, что, как правило, "истинный" механизм функиионирования объекта исследования остается для исследователя скрытым, а изучение свойств отдельных составляющих объекта исследования в нужной степени невозможно. Однако и в таких случаях необходимость применения в исследовании соответствующих моделей, причем сам объект исследования представляется как некий "черный ящик".

Одной из разновидностей видов моделирования, который учитьвает и присущие определенному субъекту особенности восприятия ситуации, и нечеткость описания ситуации и объекта моделирования, $и$ базируется на применении формальных методов, является когнитивное моделирование.

В статье рассматривается когнитивная модель научно-технической сферы как составляюшей обеспечения военной безопасности государства. На основе известной модели рассмотрень способы 
определения структуры и параметров модели, ее применение для определения наиболее влиятельных факторов на цели функционирования системы, а также способы модификации модели для учета текущих реалий.

Ключевые слова: военная безопасность государства, когнитивная модель, лингвистические переменные, вектор целей, вектор управления.

\title{
MODEL OF SCIENTIFIC AND TECHNICAL SPHERE OF THE STATE MILITARY SECURITY SYSTEM
}

\author{
Olena Derhylova (Candidate of Technical Sciences, Senior Researcher)
}

\section{National Defence University of Ukraine named after Ivan Cherniakhovskyi, Kyiv, Ukraine}

In the absence of a complete theory in the chosen subject area, the indispensable tool of the researcher remains the model of the object or phenomenon to be studied. Despite the specific features of the model, it should be noted that the process of obtaining the required model is always based on a careful study of the original object. If the mechanism of functioning of the original object is available for disclosure and understanding, and its individual components are subject to full (within the study) study, then it is natural to build and further apply a simulation model.

But the theory of military security of the state deals with objects and phenomena, the properties of which to varying degrees, but always depend on the "human factor", so it is difficult to formalize. This fact means that, as a rule, the "true" mechanism of functioning of the object of study remains hidden from the researcher, and the study of the properties of individual components of the object of study is impossible to the necessary extent. However, even in such cases, there is a need to use appropriate models in the study, and the object of study is presented as a kind of "black box".

Cognitive modeling is one of the types of modeling that takes into account both the peculiarities of the perception of the situation and the vagueness of the description of the situation and the object of modeling, and is based on the use of formal methods.

The article considers the cognitive model of the scientific and technical sphere as a component of ensuring the military security of the state. Based on the known model, the methods of determining the structure and parameters of the model, its application to determine the most influential factors for the functioning of the system, as well as ways to modify the model to take into account current realities.

Key words: military security of the state, cognitive model, linguistic variables, vector of purposes, vector of management.

\section{References}

1. Bogdanovich V. Yu. Teoreticheskie osnovyi analiza problem natsionalnoy bezopasnosti gosudarstva $\mathrm{V}$ voennoy sfere: Monografiya / Bogdanovich V. Yu. // - K. : Osnova, 2006. - $296 \mathrm{~s}$.

2. Kosevtsov V. O. Metodichniy pIdhId do analIzu y otsInki rIvnya natsIonalnoYi bezpeki ta YiYi skladovih / Kosevtsov V. O., BInko I. F., MatvIEvskiy O. M. //

Nauka I oborona. - 1995. - № 1. - S. 74-77.

3. Makarenko D.I., Hrustalev E.Yu. Kontseptualnoe modelirovanie voennoy bezopasnosti gosudarstva / D.I. Makarenko, E.Yu. Hrustalev; Tsentr, ekon.-mat. in-t RAN; In-t problem upravleniya im. V.A. Trapeznikova RAN. - M.: Nauka, 2008. - 303 s. 